\title{
Design and Simulation of Reasonable Layout Model of Green Landscape
}

\author{
Na Zhang ${ }^{1, a}$ \\ ${ }^{1}$ Wuhan Institute of Design and Sciences, Wuhan, Hubei, 430200 \\ a email
}

\author{
Keywords: PSR Model, Reasonable Layout Model, Green Landscape
}

\begin{abstract}
Rational landscape pattern is a reflection of a city's economic development and social prosperity of the window, so the rationality of landscape pattern has a very important practical significance in terms of functionality, such as the humanities and future development. Traditional Landscape Pattern rationality mainly landscape index and microscopic methods to index-based landscape-based, remote sensing image as its main material, the lack of economic, cultural, environmental and political aspects of the city's exam consideration, so landscape index analysis by such methods rationality landscape pattern has certain limitations. In order to better evaluate the reasonableness of the landscape pattern, landscape index method combined with the present study, eco-efficiency and environmental capacity as well as economic, social and other factors put forward reasonable macro pattern recognition method of landscape pattern a comprehensive index system, from a broader perspective of rationality landscape pattern.
\end{abstract}

\section{Introduction}

Connotation of land and landscape are two different but similar extension of the concept in landscape ecology, as its object of study, landscape refers to the Earth's surface structure and function within a certain spatial range of natural and human elements of a unified regional complex. From this point of view look, and the concept of land, are complex area, both on the extension of the concept is basically the same at the same time, both in the implications of the concept of the essential difference: the concept focuses on this area of land complex socio-economic properties, including property rights to land, fertile extent of land use and economic values; landscape concept focuses on the aesthetic value of this complex area of ecological value and bring long-term benefits of mankind, has a greater meaning additional, it can be seen from the development of landscape ecology, landscape ecology is the study on land of landscape ecology arising from Troll East Africa utilization of aerial photographs of land use, land has been the main object of study of landscape ecology. Development and utilization of land, land management and land ecological restoration issue has been the development of landscape ecology in the closely watched. Application of modern landscape ecology land use mainly concerned about the impact of the material flow and energy flow of land use, is to analyze the relationship between landscape pattern and ecological processes, and closely related to land use planning space layout, is the theoretical basis for land use planning and management.

\section{Landscape Pattern Reasonableness Description}

Schaltegger and Sturm first proposed the concept of eco-efficiency, ie the ratio of added value and increased environmental impact; in 1992 the World Business Council for Sustainable Development proposed "eco-efficiency" concept, the "eco-efficiency must offer competitive prices advantages, to meet human needs and to ensure the quality of life of the product or service, while gradually reducing the product or service life cycle ecological impact and resource consumption intensity, which reduces to the extent consistent with the estimated carrying capacity of the Earth ", so for a city in terms of eco-efficiency is in certain natural resources, as much as possible to produce economic benefits, while reducing environmental costs.

Calculation methods of ecological efficiency is mainly value - impact ratio method to calculate the two parts including the calculation of economic value and environmental impact, in addition, 
there are other methods of calculation, such as data envelopment analysis, the value of ecological costs exponential model. In this study, the main impact of a use value ratio calculation method, the expression is:

Eco-efficiency $=$ Product or Service Value / Impact of The Environmental Impact $=$ Value $/$

Environmental Impacts of Increased

Value of the product or service, there are two main methods to calculate cost-benefit analysis (Cost-Benefit Analysis, CBA), and life-cycle cost analysis (Life Cycle Costing, LCC). Among them, the cost-benefit analysis to calculate the costs and benefits associated economic costs and environmental externalities within the entire life cycle of the product market, and life-cycle cost analysis only calculated the costs and benefits related to the market the entire product life cycle. Calculated the environmental impact of computing, the current standard in the selection method IS014001 environmental performance evaluation parameters used in eco-efficiency of environmental impact. Environmental performance parameters and performance parameters, including management operational performance parameters, it is the expression of a particular form of the performance of the organization's environment-related information.

\section{Landscape Pattern of Rationality PSR Model}

PSR model is usually statistic social, economic and natural factors, and these statistics on the use of the model in the process, often encounter two problems: First, different statistical data, often with a different dimension, and for difficulties in terms of a mold, enter a different dimension is clearly unreasonable. The second problem is the relatively large amount of data, how to determine the weight of it, that the evaluation model, how to distinguish the importance of each parameter value. So in other PSR mold build process, you must go to solve these two problems.

For the first question, all kinds of commonly used mathematical methods for the same data normalized by 0 to 1 or $-1-1$ other methods to eliminate dimensional data, relatively speaking, the data normalization relatively simple, the current Matlab software has provided more mature normalization algorithm. For the second question, how to determine the parameters of weight, which is a major key PSR model can generally be divided into subjective determination, mathematical method to determine the number of subjective and objective method for determining the plus mathematics. At present the main methods of transformation matrix, multiple criteria to judge (MCE), Analytic Hierarchy Process (AHP) and gray model, principal component analysis, adaptive-mode concept, artificial neural networks, decision trees and other methods. Many studies focus only on the geometric characteristics of landscape pattern analysis and description, but ignores the affected area to its characteristic landscape patterns, resulting in the landscape pattern and reasonable evaluation of A? Limitations of rationality landscape pattern landscape are composed of units of the class concept, etc. the number and spatial distribution and configuration of scientific and reasonable, and to promote the city to achieve ecological and economic sustainability.

Because of different indicators, generally it has a different dimension, during the comprehensive evaluation, in order to more rational response to the role of each of the index, usually the various indices by dimension treatment for all the upcoming data "standardized." There are a variety of data indicators standardized methods and standardized methods preclude the use of formula 1 and 2 in this study:

$$
\mathrm{y}_{i j}=\left\{\begin{array}{cc}
1 & x_{i j}=x_{\max } \\
\frac{x_{i j}-x_{\min }}{x_{\max }-x_{\min }} & x_{\min }<x_{i j}<x_{\max } \\
0 & x_{i j}=x_{\min }
\end{array}\right.
$$




$$
\mathrm{y}_{i j}=\left\{\begin{array}{cc}
1 & x_{i j}=x_{\min } \\
\frac{x_{\max }-x_{i j}}{x_{\max }-x_{\min }} & x_{\min }<x_{i j}<x_{\max } \\
0 & x_{i j}=x_{\max }
\end{array}\right.
$$

Study on the raw data matrix isrepresented by $\mathrm{X}$, denoted by $\mathrm{r}$ normalized data matrix, where $X=\left\{x_{i j}\right\}_{m \times n}, Y=\left\{y_{i j}\right\}_{m x n}$, m represents the number of years, $\mathrm{N}$ represents the number of indicators. While indicators are divided into positive and negative indicators index, the so-called positive indicators, that the larger the index value, the better the result of the evaluation index. The so-called negative index, that is to say the larger the index value, the worse the results of the evaluation index. Equation (1) as a positive indicator, Equation (2) is a negative indicator.

In the PSR model, each of the evaluation results of the evaluation of the impact is not the same size, in order to reasonably consider the importance of each indicator to evaluate the impact of the results, you must determine the weight of each index weight. In an indicator for determining the weight of the process, there is usually a subjective law and objective law and subjective and objective method of combining. Subjective methods are as expert scoring method and AHP, etc. The main objective method has variable coefficients, correlation coefficient and entropy method. Subjective sense of subjective law is heavy, difficult to grasp, so good can be more objective method to determine the weight. Of course, if combined with subjective and objective method, you may get better results of the evaluation. In the present study, based on limited conditions, objective approach - entropy method to strike weights. "Entropy" is not about information theory measure "uncertainty", the greater the amount of information, the smaller the uncertainty, entropy is smaller. It is possible to eliminate the influence of subjective factors to a certain extent by the entropy method, according to the definition of cannon, the first $\mathrm{j}$ impact indicators a message digest factor can be calculated as follows:

$$
e_{i}=-k \sum_{i=1}^{i=m}\left(y_{i j} \ln y_{i j}\right)
$$

Among them, $k=1 / \ln m$, standardized data is $\mathrm{y}_{i j}$, if $\mathrm{y}_{i j}$ is less than 0 , then take a small number of 0.00001 instead of calculating.

$$
w_{j}=\frac{d_{j}}{\sum_{i=1}^{n} d_{j}}
$$

For each indicator, its entropy is smaller, then the greater the difference, the more important indicators. So we can through the study found that the reaction entropy change of an indicator in the calendar year, if the change the greater the entropy also smaller.

\section{Evaluation Results of the Reasonableness Model}

According to the above theory, comprehensive evaluation index can be calculated for a given year of the study area A. In addition, taking into account the comprehensive evaluation index is between 0 and 1 , and is closer to 1 the more reasonable, so the landscape pattern index determining reasonableness standard classification Table 1 . Reasonableness determination index rating and comments based on landscape pattern of Table 1, it can determine a given year landscape pattern reasonable. 
Table 1 Landscape Pattern reasonableness determination index rating

\begin{tabular}{|c|c|c|}
\hline Composite Index & Result & Comment \\
\hline$<0.35$ & Very Unreasonable & $\begin{array}{l}\text { Forward index is low, a negative index is } \\
\text { high, the need to improve all aspects of } \\
\text { environmental, cultural and economic. }\end{array}$ \\
\hline $0.35 \sim 0.45$ & Unreasonable & $\begin{array}{l}\text { Composite Index lower, indicating poor in } \\
\text { certain areas, or in general is not very } \\
\text { good, you need to determine the cause, to } \\
\text { be improved }\end{array}$ \\
\hline 0.450 .65 & A little Reasonable & $\begin{array}{l}\text { A little reasonable, the need for further } \\
\text { improvement }\end{array}$ \\
\hline $0.65 \sim 0.75$ & Reasonable & Index higher, rational arrangement \\
\hline$>0.75$ & Very Reasonable & $\begin{array}{l}\text { Very reasonable and promote the } \\
\text { development of society }\end{array}$ \\
\hline
\end{tabular}

Reasonable evaluation index system of landscape pattern, the response from each of the indicators are different aspects of the rationality of the landscape pattern by building landscape pattern and reasonable evaluation system, the overall level of the city can be evaluated from a multifaceted overall up justify the landscape pattern. At the same time according to the city together with the landscape pattern of ecological, economic and social aspects of the relationship, said combining satellite remote sensing image, good management and forecasting ecosystems to human activities useful spatial information, so as to promote a more rational landscape pattern configuration.

In addition to a number of subjective factors of social, economic and other aspects will affect the landscape pattern of rational distribution and the precision of this study is also affected by the following aspects:

Spatial and spectral resolution is remote sensing images. This study selected only LandsatTM5 image due to the limitations of the data source that is. Numerous studies and practical application have proven that shortwave infrared TM5 (spectral range 155 (M750nm) or radar data microwave band are highly sensitive to water bodies such as Data Sources The abundant, should be a comprehensive selection of many types of remote sensing data, through the analysis and comparison of selected the best band for the target area, it will undoubtedly get more accurate monitoring results .TM the visible spatial resolution of $30 \mathrm{~m}$, this study in order to reduce differences in bands of image resolution, the TM data conducted a re-sampling to a resolution unified 60m; then the TM data registration, while not leading to false-color composite image with a resolution of only $60 \mathrm{~m}$, to a certain extent, reduce the error performance.

In this study, supervised classification achieved good results, the classification accuracy of $90 \%$ lead to the presence of $10 \%$ error rate in the study area is mainly due to grassland, arable land distributed widely, it is difficult to distinguish. If using shortwave infrared or radar data, it will be possible to improve the classification accuracy.

Image Rectification and precision coastline digitized maps (remote sensing and imaging applications related to scale). This study using a 1: 1 million scale remote sensing image interpretation mapping is 1: 500000 scale, the control point 15, geometric correction error is less than equal to 0.0508 pixels; it is the geometric error of less than Im. Furthermore, PSR model is realized through a number of evaluation models and formulas related indicators, no documents related to the specific method to make this model the accuracy of the analysis, so the accuracy of PSR model analysis can be ignored. Although the present study, data acquisition, there may be differences with the actual situation of the processing and model building process, but the final results from the analysis is that substantially reflect the impact of the reasonableness of the landscape pattern factor, as well as various landscape spatial distribution trends. This study shows the method of PSR model can better meet the landscape pattern and reasonable evaluation needs. 


\section{Conclusion}

Regional land use change the overall trend of landscape aggregation increase, decrease landscape diversity Landscape diversity is a source of stability of the landscape, down regional land use landscape diversity indices showed that the spatial pattern of landscape stability index of regional land use is reduced. from an ecological perspective the evolution of the system itself, the natural state of ecosystems always gradually evolved from unstable to stable, that is, land use pattern from Enshi naturally exist from the perspective of woodland to cropland, grassland reverse evolution trend, this is eco-statehood Enshi not allowed. Therefore, we should prevent this reverse evolution of regional land use system, the need to further strengthen the work of returning farmland to forest and natural forest protection, which requires state and local government Returning Farmland I'm a long-term policy to support the development of long-term mechanism of returning farmland to forests, returning farmland to forest and stable outcomes achieved.

\section{References}

[1] Ahem J. Planning for an extensive open space system: linking landscape structure and function [J]. Landscape and urban planning 1991, 21 (1): 131-145.

[2] Flores A, Pickett ST, Zipperer WC, et al Adopting a modern ecological view of the metropolitan landscape: The case of a green space system for the New York City region [J]. Landscape and Urban Planning 1998, 39 (4): 295-308.

[3] Farina A. Principles and methods in landscape ecology: Towards a science of the landscape [M]. Springer, 2007

[4] Riitters K H, O'Neill R V, Hunsaker C T, et al A factor analysis of landscape pattern and structure metrics [J]. Landscape ecology 1995,10 (1), 23-39.

[5] Cushman S A, Mcgarigal K, Neel M C. Parsimony in landscape metrics: Strength, universality, and consistency [J]. Ecological indicators 2008, 8 (5): 691-703. 